\title{
Psychometric Properties of The Health-Promoting Lifestyle Profile II: Validation of the Self-Realization and Health Responsibility Constructs Among Kenyan University Students
}

\author{
Oloo Micky Olutende ${ }^{1 *}$, Dr. Maximilla N. Wanzala ${ }^{2}$, Prof. Edwin K. Wamukoya ${ }^{1}$ \\ ${ }^{1}$ Department of Health Promotion and Sports Science, Masinde Muliro University of science and Technology Kakamega, Kenya \\ ${ }^{2}$ Department of Public Health, Masinde Muliro University of Science and Technology Kakamega, Kenya
}

\author{
DOI: $10.36348 /$ sjnhc.2019.v02i11.004 \\ *Corresponding author: Oloo Micky Olutende
}

| Received: 08.11.2019 | Accepted: 15.11.2019| Published: 15.11.2019

\section{Abstract}

Objective: The main aim of this study was to establish psychometric properties of the subscales self-realization and health responsibility of the health-promoting lifestyle profile II tool among Kenyan university students Design: The study design was a cross-sectional analytical, that utilized quantitative methods Setting. The study was conducted in Kakamega County, located in Western Kenya. Analysis: Data were analyzed through confirmatory factor analysis, which was conducted using robust maximum likelihood estimation. The factor model was tested for validity and construct validity. Main outcome measures: subscales self-realization and health responsibility of the Health-Promoting Lifestyle Profile II Results: The items for self-realization and health responsibility had a Cronbach's alpha coefficient of 0.72 and 0.80 , indicating acceptable reliability. For self-realization, the results of the Chi-square goodness of fit test were significant, $\chi 2(27)=251.61, \mathrm{p}<.001$, suggesting that the model did not adequately fit the data. The fit indices showed the RMSEA index was greater than $.10, \mathrm{RMSEA}=0.20,90 \% \mathrm{CI}=[0.18,0.22]$, which is indicative of a poor model fit The CFI was less than $.90, \mathrm{CFI}=0.52$, suggesting that the model is indicative of a poor model fit. For health responsibility, the results of the Chi-square goodness of fit test were significant, $\chi 2(20)=272.58, p<.001$, suggesting that the model did not adequately fit the data. Fit indices values showed the RMSEA index was greater than .10, RMSEA $=0.25,90 \% \mathrm{CI}=[0.22,0.27]$, which is indicative of a poor model fit. The CFI was less than $.90, \mathrm{CFI}=0.75$, suggesting that the model is indicative of a poor model fit. Conclusion: In conclusion, within the limitations of this study, the results showed that confirmatory factor analysis could not well fit the items to their latent constructs. This study recommended that in future studies, a shortened version of this tool is subjected to psychometric investigation.

Keywords: Confirmatory factor analysis, Construct validity, Health-promoting behaviors, Health-Promoting Lifestyle Profile-II, Undergraduate students, Non-communicable diseases, Kakamega, Kenya.

Copyright @ 2019: This is an open-access article distributed under the terms of the Creative Commons Attribution license which permits unrestricted use, distribution, and reproduction in any medium for non-commercial use (NonCommercial, or CC-BY-NC) provided the original author and source are credited.

\section{INTRODUCTION}

Health promotion is defined as the process of enabling people to increase control over and to improve an individual's health (World Health Organization [WHO] [1]. Health promotion, as reflected in a healthy lifestyle, is an integral part of disease prevention [2,3]. Among the determinants of health, has been acknowledged as the basic way of preventing disease, especially chronic disease, so health-promoting behavior and lifestyle should be considered the main strategy to maintain and improve health [4]. Studies show that a higher level of health-promoting behavior correlates with a lower mortality rate [5]. Research showed that unhealthy lifestyles are widespread among young adults and they suffered from poor dietary habits $[6,7]$. In Kenya, research shows that NCDs have been a growing problem over the years [8, 9]. In 2012 NCDs accounted for more than $50 \%$ of total hospital admissions and over 55\% hospital deaths in Kenya [9]. A study by Machio [9] showed that NCDs reduced labor force participation by $61 \%$ but with elimination of physical inactivity, life expectancy in Kenya was expected to increase by between $0.25-0.49$ years [10].

Research necessitates the use of reliable and valid measurement tools for assessing health-promoting behavior. The Health-Promoting Lifestyle Profile II (HPLP-II) is a widely-used instrument for evaluation of health behavior $[11,12]$. The Health Promoting Lifestyle Profile II (HPLP - II) questionnaire is the revised version of the HPLP questionnaire and was first designed by Walker et al. [13]. It has been translated 
into different languages, including Spanish, Japanese, Arabic, Chinese, and Turkish [14-16] and its validity and reliability have been verified. Furthermore, Cronbach's alpha coefficients for its subscales were suitable too, as in other studies $[17,18]$. It is based on Pender's Health Promotion Model, it conceptualizes an individual's health-promoting lifestyle in terms of the following dimensions; health responsibility, physical activity, nutrition, spiritual growth, interpersonal relations, and stress management.

There are no adequate tools to assess health behaviors in young adults in Kenya, it is necessary that the tool is localized in order to measure the lifestyle of the young adults and evaluate health-promoting behavior so that it can be used in planning the health field. Obtaining an accurate and equivalent crosscultural assessment of a psychological construct has been considered a key element of research, since the same construct may differ across countries and contexts [19]. In this research, the validity and reliability of the HPLP-II questionnaire for the Kenyans students were examined. The main aim of this study was to establish psychometric properties of the subscales self-realization and health responsibility of health-promoting lifestyle profile II tool.

\section{METHODS}

This was a cross-sectional study; surveys were conducted between January and May 2019. Sampling was conducted by convenience sampling method and university students at the campus at time of data collection were sampled. The eligibility criteria were as follows: I) must be a university student; II) able to communicate in writing; III) Kenyan nationality; IV) provided informed consent to participate in the study. Exclusion criteria were lack of consent, the inability to complete the questionnaires due to any reasons put forth and participation in other research studies. No further approval was needed since the project did not require access to patients or personal data. All participants were informed of the complete confidentiality of the data and were notified of the subsequent handling of the data following analysis.

\section{Participants}

The study population was university students in Kenyan public university. A wide range of recommendations regarding sample size in factor analysis has been made. Some authors [20] suggest that 100 respondents are the absolute minimum number to be able to undertake factor analysis. Others would suggest that an adequate sample size for confirmatory factor analysis (CFA) considered $n \geq 200$ [21]. There is also a rule of thumb of five respondents per item [22]. For this study the researchers opted for 4 participants per item, hence it was necessary to recruit at least 208 students $(4 \times 52$ items). The majority were female $(80.3 \%, \mathrm{n}=167)$. The majority were below the age of 21 years. The mean age of the participants was 21 years old $(\mathrm{SD}=1.3)$. Most of the participants were first years $(33 \%, \mathrm{n}=68)$.

\section{Measures}

The HPLP II is a 52-item 4-point Likert scale (never, sometimes, often, and routinely) tool based on Pender's health promotion model which contains 6 subscales [23]; self-realization (SR) (9 items), health responsibility (HR) (9 items), physical activity (PA),8 items),nutrition (N) $(9$ items), interpersonal relations $(\mathrm{IR})(9$ items) and stress management SM) (8 items). The HPLP-II focuses on self-initiated actions and perceptions that serve to maintain or enhance the level of wellness, self-actualization, and fulfillment of the individual [24]. The HPLP-II has been translated into different languages and widely used in other studies $[25,17,26]$. The internal consistency Cronbach alpha for the original English version of HPLP-II was satisfactory, with 0.94 for the total scale of HPLP-II, and from 0.79 to 0.87 for its six subscales [24]. A validity and reliability study concerning HPLP II in Turkey was carried out by Bahar et al. [27] who used 52 items. The HPLP II was translated from English to Turkish by Bahar et al. [27] Cronbach Alpha coefficient of the HPLP II was 0.92 and had high reliability. The reliability coefficient was 0.77 for the sub-scale health responsibility, 0.79 for physical activity, 0.68 for nutrition, 0.79 for self-realization, 0.80 for interpersonal relationships, and 0.64 for stress management [27].

Question numbers of subscale related to selfrealization are $6,12,18,24,30,36,42,48$, and 52 in HPLP II. This subscale includes nine items that can be taken at the lowest point which is " 9 " and the highest is "36". The question numbers of subscale related to health responsibility are $3,9,15,21,27,33,39,45$ and 51 in HPLP II. This subscale includes nine items that can be taken at the lowest point is "9", the highest is "36".

\section{DATA ANALYSIS}

All questionnaires included in the study were completed without any missing values. Multivariate normality assumption was checked, and results indicated that the data did not meet the assumption, based on Mardia multivariate skew $(p<0.001)$ and kurtosis $(\mathrm{p}<0.001)$ tests. Therefore, for the subsequent confirmatory factor analysis (CFA), the robust maximum likelihood estimator (MLR) was utilized, as this is robust to non-normality. To achieve good psychometric characteristics, high standardized factor loadings (> 0.40) are preferred [28]. Therefore, items with factor loadings less than 0.40 were examined and treated as potentially problematic items. Problematic items would be omitted only with adequate theoretical support. According to Hair et al. reporting various fit indices are necessary because there are no standard rules for assessment of model fit [29]. Based on the 2factor structure and 18-item measurement model in the present study, the fit indices and its acceptable threshold 
value are as follows: the comparative fit index (CFI) and Tucker and Lewis index (TLI) with the desired value of more than 0.90; the root mean square error of approximation (RMSEA) with a desired value of less than 0.08; probability RMSEA with the desired value of more than 0.05; and the standardized root mean square (SRMR) with a desired value of less than 0.08 [29]. The construct reliability $(\mathrm{CR})$ in a latent variable modeling approach was calculated for each factor in HPLP-II-M based on CR formula listed in a published study by Raykov and Marcoulides in 2015. The acceptable value of CR is above 0.70 [29]. Discriminant validity was checked by inspecting the correlation between the factors in the model. Discriminant validity is established when the correlation between factors is below 0.85. In addition, to determine the internal consistency, Cronbach's alpha coefficient was used. Accepted values for Cronbach's alpha coefficient and ICC 0.7 are more considered [30, 31]. Discriminant validity was proven as the results of the correlation between factors were significant and $\mathrm{r} \leq 0.85$.

\section{RESULTS}

Demographic summary statistics were calculated for each interval and ratio variable. Frequencies and percentages were calculated for each nominal variable. The most frequently observed category of Gender was Female $(n=167,80 \%)$. The most frequently observed category of Age groups was 21 years or below $(n=138,66 \%)$. The most frequently observed category of Year was First Year $(n=68$,
$33 \%)$. Frequencies and percentages are presented in Table 1.

Table-1: Frequency Table for Nominal Variables

\begin{tabular}{|l|l|l|}
\hline Variable & $\boldsymbol{n}$ & $\boldsymbol{\%}$ \\
\hline Gender & & \\
\hline Female & 167 & 80.29 \\
\hline Male & 41 & 19.71 \\
\hline Age groups & & \\
\hline 22 years or above & 70 & 33.65 \\
\hline 21 years or below & 138 & 66.35 \\
\hline Year & & \\
\hline Second Year & 50 & 24.04 \\
\hline Third Year & 41 & 19.71 \\
\hline First Year & 68 & 32.69 \\
\hline Fourth-year & 49 & 23.56 \\
\hline
\end{tabular}

Note. Due to rounding errors, percentages may not equal $100 \%$.

The observations for Age had an average of $20.98\left(S D=1.29, S E_{M}=0.09\right.$, Min $=19.00$, Max $=$ 24.00, Skewness $=0.30$, Kurtosis $=-0.95, M d n=21.00$, Mode $=20.00$ ). When the skewness is greater than 2 in absolute value, the variable is considered to be asymmetrical about its mean. When the kurtosis is greater than or equal to 3, then the variable's distribution is markedly different than a normal distribution in its tendency to produce outliers [32]. The summary statistics can be found in Table 2 .

Table-2: Summary Statistics Table for Interval and Ratio Variables

\begin{tabular}{|l|l|l|l|l|l|l|l|l|l|l|}
\hline Variable & $\boldsymbol{M}$ & $\boldsymbol{S D}$ & $\boldsymbol{n}$ & $\boldsymbol{S E}_{\boldsymbol{M}}$ & Min & Max & Skewness & Kurtosis & $\boldsymbol{M d n}$ & Mode \\
\hline Age & 20.98 & 1.29 & 208 & 0.09 & 19.00 & 24.00 & 0.30 & -0.95 & 21.00 & 20.00 \\
\hline
\end{tabular}

Note. '-' denotes the sample size is too small to calculate the statistic.

\section{Reliability}

A Cronbach alpha coefficient was calculated for the Self-realization scale, consisting of SR1, SR2, SR3, SR4, SR5, SR6, SR7, SR8, and SR9. The Cronbach's alpha coefficient was evaluated using the guidelines suggested by George and Mallery [33] where
$>.9$ excellent, > .8 good, > .7 acceptable, > .6 questionable, $>.5$ poor, and $\leq .5$ unacceptable. The items for Self-realization had a Cronbach's alpha coefficient of 0.72 , indicating acceptable reliability. Table 3 presents the results of the reliability analysis.

Table-3: Reliability Table for Self-realization

\begin{tabular}{|l|l|l|l|l|}
\hline Scale & No. of Items & $\boldsymbol{\alpha}$ & Lower Bound & Upper Bound \\
\hline Self-realization & 9 & 0.72 & 0.66 & 0.77 \\
\hline
\end{tabular}

Note. The lower and upper bounds of Cronbach's $\alpha$ were calculated using a $95.00 \%$ confidence interval.

A Cronbach alpha coefficient was calculated for the Health responsibility scale, consisting of HR1, HR2, HR3, HR4, HR5, HR6, HR7, HR8, and HR9. The Cronbach's alpha coefficient was evaluated using the guidelines suggested by George and Mallery [33] where $>.9$ excellent, > .8 good, > .7 acceptable, > .6 questionable, $>.5$ poor, and $\leq .5$ unacceptable. The items for Health responsibility had a Cronbach's alpha coefficient of 0.80 , indicating good reliability. The following variables were negatively correlated with Health responsibility: HR4. These variables were automatically reverse coded to improve reliability. Table 4 presents the results of the reliability analysis. 
Table-4: Reliability Table for health Responsibility

\begin{tabular}{|l|l|l|l|l|}
\hline Scale & No. of Items & $\alpha$ & Lower Bound & Upper Bound \\
\hline health Responsibility & 9 & 0.80 & 0.77 & 0.83 \\
\hline
\end{tabular}

Note. The lower and upper bounds of Cronbach's $\alpha$ were calculated using a 95.00\% confidence interval

\section{Confirmatory Factor Analysis (CFA)}

A CFA model was conducted to determine whether the latent variable, Self-realization, adequately describes the data. Maximum likelihood estimation was performed to determine the standard errors for the parameter estimates.

\section{Assumptions}

\section{Multivariate normality}

To assess the assumption of multivariate normality, the squared Mahalanobis distances were calculated for the data and plotted against the quantiles of a Chi-square distribution [34]. In the scatterplot, the solid line represents the theoretical quantiles of a normal distribution. Normality can be assumed if the points form a relatively straight line. The scatterplot for normality is presented in Figure 1.

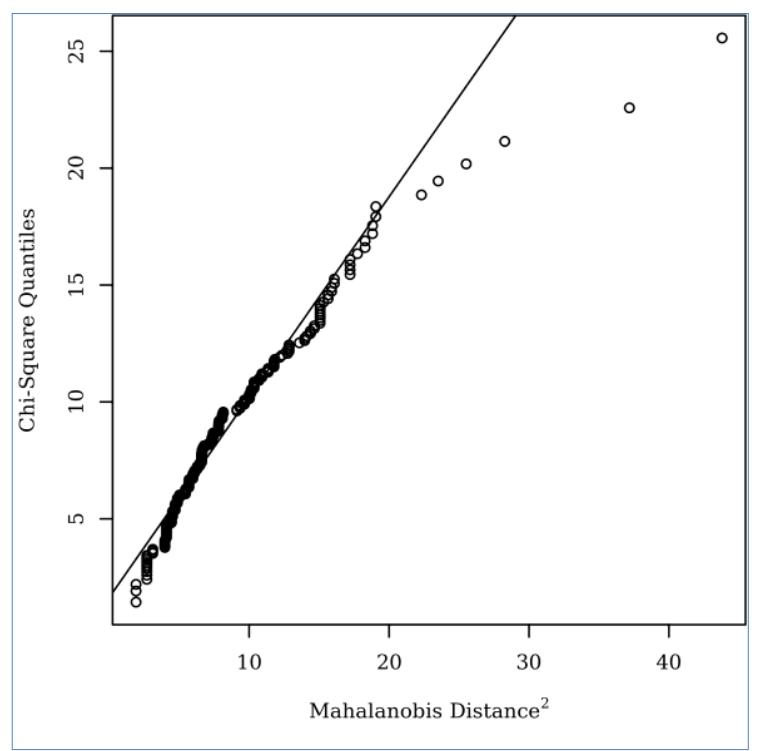

Fig-1: Mahalanobis distance scatterplot testing multivariate normality

\section{Multivariate Outliers}

To identify influential points in the data Mahalanobis distances were calculated and compared to a $\chi^{2}$ distribution [35]. An outlier was defined as any Mahalanobis distance that exceeds 27.88, the .999 quantile of a $\chi^{2}$ distribution with 9 degrees of freedom [36]. There were 3 observations detected as outliers.

\section{Multicollinearity}

Although variables should be correlated with one another to be considered suitable for factorization, variables that are too highly correlated can cause problems in CFA. To assess multicollinearity, the squared multiple correlations were inspected and the determinant of the correlation matrix was calculated. Any variable with an $R^{2}>.90$ can contribute to multicollinearity in the CFA model [36]. Variables that exhibit high multicollinearity should either be removed from the analysis or combined as a composite variable. There were no variables that had an $R^{2}>90$. Another assessment for multicollinearity is to assess the determinant of the data's correlation matrix. A determinant that is $\leq 0.00001$ indicates that multicollinearity exists in the data [37]. The value of the determinant for the correlation matrix was 0.0901, indicating that there was no multicollinearity in the data.

First, the reliability of the analysis was tested based on the sample size used to construct the model. Next, the results were evaluated using the Chi-square goodness of fit test and fit indices. Lastly, the squared multiple correlations $\left(R^{2}\right)$ for each endogenous variable were examined. The results of the CFA model are presented in Table 5. The node diagram is shown in Figure 2.

Table-5: Unstandardized Loadings (Standard Errors), Standardized Loadings, and Significance Levels for Each Parameter in the CFA Model $(\mathbf{N}=\mathbf{2 0 8})$

\begin{tabular}{|l|l|l|l|}
\hline Parameter Estimate & Unstandardized & Standardized & $\boldsymbol{p}$ \\
\hline Error in Self-Realization & $0.46(0.09)$ & 1.00 & $<.001$ \\
\hline Error in SR1 & $0.45(0.06)$ & 0.49 & $<.001$ \\
\hline Error in SR2 & $0.50(0.06)$ & 0.69 & $<.001$ \\
\hline Error in SR3 & $0.34(0.04)$ & 0.77 & $<.001$ \\
\hline Error in SR4 & $0.23(0.02)$ & 0.77 & $<.001$ \\
\hline Error in SR5 & $0.68(0.07)$ & 0.95 & $<.001$ \\
\hline Error in SR6 & $0.44(0.05)$ & 0.86 & $<.001$ \\
\hline Error in SR7 & $0.51(0.06)$ & 0.70 & $<.001$ \\
\hline Error in SR8 & $0.68(0.08)$ & 0.65 & $<.001$ \\
\hline Error in SR9 & $0.43(0.04)$ & 0.93 & $<.001$ \\
\hline
\end{tabular}

Note. $\chi^{2}(27)=251.61, p<.001 ;--$ indicates the statistic was not calculated due to parameter constraint. 


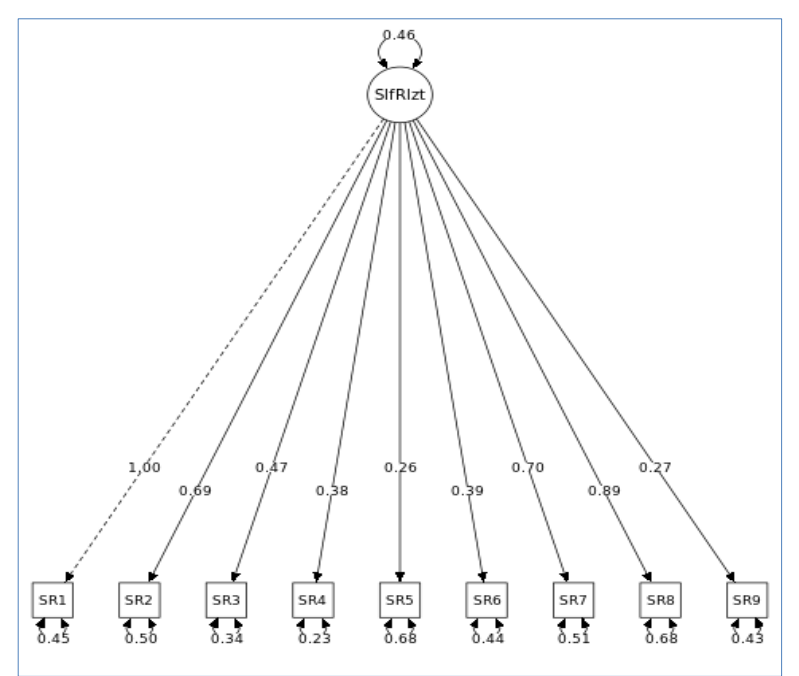

Fig-2: Node diagram for the CFA model

There are a variety of ways to measure if the CFA model adequately describes the data. The Chisquare statistic is the most popular statistic used to measure the model fit. Besides the Chi-square statistic, fit indices are also used to help researchers determine if the factor analysis model fits the data properly. Along with the Chi-square goodness of fit test, the following fit indices were used to assess the model fit: root mean square error of approximation (RMSEA), comparative fit index (CFI), Tucker-Lewis index (TLI) and standardized root mean square residual (SRMR). Goodness of fit test. A Chi-square goodness of fit test was conducted to determine if the CFA model fits the data adequately. It is standard practice for CFA to include the Chi-square test. However, this test is sensitive to sample size, which causes the test to almost always reject the null hypothesis and indicate a poor model fit when the sample size is large [38]. The results of the Chi-square goodness of fit test were significant, $\chi^{2}(27)=251.61, p<.001$, suggesting that the model did not adequately fit the data. Fit indices. The RMSEA index was greater than .10 , RMSEA $=0.20,90 \% \mathrm{CI}=$ $[0.18,0.22]$, which is indicative of a poor model fit [38]. The CFI was less than $.90, \mathrm{CFI}=0.52$, suggesting that the model is indicative of a poor model fit [38]. The TLI was less than .95 , TLI $=0.36$, which is indicative of a poor model fit [38]. The SRMR was greater than .08,
SRMR $=0.11$, which implies that the model fits the data poorly [38]. The fit indices are presented in Table 6.

Table-6: Fit Indices for the CFA model

\begin{tabular}{|l|l|l|l|l|}
\hline NFI & TLI & CFI & RMSEA & SRMR \\
\hline 0.50 & 0.36 & 0.52 & 0.20 & 0.11 \\
\hline
\end{tabular}

Note. RMSEA $90 \% \mathrm{CI}=[0.18,0.22]$; -- indicates that the statistic could not be calculated.

The individual relationship between each indicator variable and latent variable can be assessed by the observed variable's $R^{2}$ value. The $R^{2}$ value identifies how much of the indicator variable's variance explains the factor. An $R^{2}$ value $\leq .20$ suggests that the observed variable does not adequately describe the factor and should be considered for removal from the model [38]. The following observed variables had $R^{2}$ values $\leq .20$ : SR5, SR6, and SR9. The $R^{2}$ values, along with the error variances for each observed variable are presented in Table 7.

\section{Table-7: Estimated Error Variances and $\mathbf{R}^{2}$ Values for Each Indicator Variable - Latent Variable Relationship in the CFA model}

\begin{tabular}{|l|l|l|}
\hline Endogenous Variable & Standard Error & $\boldsymbol{R}^{2}$ \\
\hline SR1 & 0.45 & 0.51 \\
\hline SR2 & 0.50 & 0.31 \\
\hline SR3 & 0.34 & 0.23 \\
\hline SR4 & 0.23 & 0.23 \\
\hline SR5 & 0.68 & 0.05 \\
\hline SR6 & 0.44 & 0.14 \\
\hline SR7 & 0.51 & 0.30 \\
\hline SR8 & 0.68 & 0.35 \\
\hline SR9 & 0.43 & 0.07 \\
\hline
\end{tabular}

Note. -- indicates the statistic could not health-promoting.

Secondly, the results of the subscale health responsibility are presented. The results were evaluated using the Chi-square goodness of fit test and fit indices. Lastly, the squared multiple correlations $\left(R^{2}\right)$ for each endogenous variable were examined. The results of the CFA model are presented in Table 8 . The node diagram is shown in Figure 4.

Table-8: Unstandardized Loadings (Standard Errors), Standardized Loadings, and Significance Levels for Each Parameter in the CFA Model $(\mathrm{N}=208)$

\begin{tabular}{|l|l|l|l|}
\hline Parameter Estimate & Unstandardized & Standardized & $\boldsymbol{p}$ \\
\hline Error in Health Responsibility & $1.30(0.13)$ & 1.00 & $<.001$ \\
\hline Error in HR1 & $0.06(0.02)$ & 0.05 & .004 \\
\hline Error in HR2 & $0.41(0.04)$ & 0.36 & $<.001$ \\
\hline Error in HR3 & $0.71(0.07)$ & 1.00 & $<.001$ \\
\hline Error in HR4 & $0.51(0.05)$ & 0.99 & $<.001$ \\
\hline Error in HR5 & $0.29(0.03)$ & 0.53 & $<.001$ \\
\hline Error in HR6 & $0.93(0.09)$ & 0.98 & $<.001$ \\
\hline Error in HR7 & $0.39(0.04)$ & 0.97 & $<.001$ \\
\hline Error in HR8 & $0.12(0.02)$ & 0.08 & $<.001$ \\
\hline
\end{tabular}

Note. $\chi^{2}(20)=272.58, p<.001 ;--$ indicates the statistic was not calculated due to parameter constraint. 


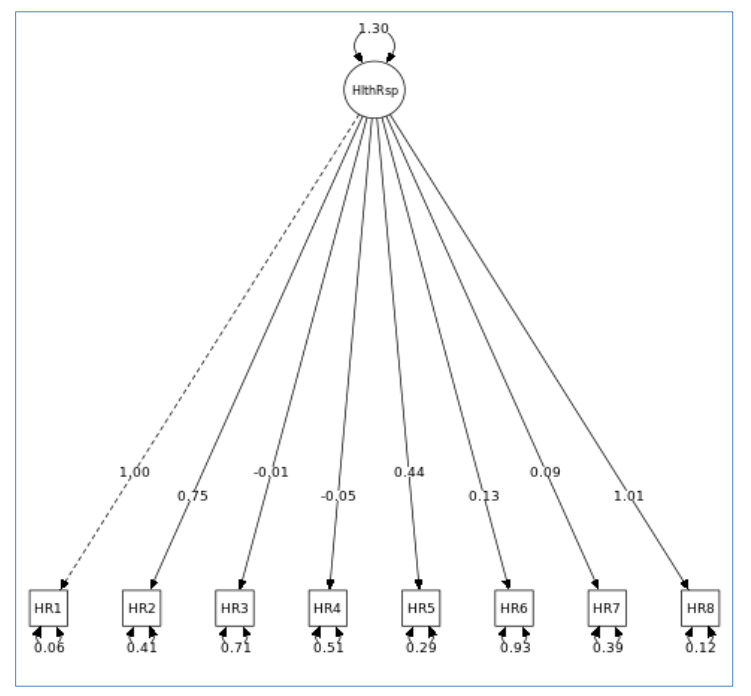

Fig-4: Node diagram for the CFA model

\section{Model fit}

Goodness of fit test. The results of the Chisquare goodness of fit test were significant, $\chi^{2}(20)=$ 272.58, $p<.001$, suggesting that the model did not adequately fit the data. Fit indices. The RMSEA index was greater than .10 , RMSEA $=0.25,90 \% \mathrm{CI}=[0.22$, 0.27 , which is indicative of a poor model fit [38]. The CFI was less than $.90, \mathrm{CFI}=0.75$, suggesting that the model is indicative of a poor model fit [38]. The TLI was less than .95 , TLI $=0.65$, which is indicative of a poor model fit [38]. The SRMR was greater than .08, SRMR $=0.13$, which implies that the model fits the data poorly [38]. The fit indices are presented in Table 9.

Table-9: Fit Indices for the CFA model

\begin{tabular}{|l|l|l|l|l|}
\hline NFI & TLI & CFI & RMSEA & SRMR \\
\hline 0.74 & 0.65 & 0.75 & 0.25 & 0.13 \\
\hline
\end{tabular}

Note. RMSEA $90 \% \mathrm{CI}=[0.22,0.27] ;$-- indicates that the statistic could not be calculated.

The individual relationship between each indicator variable and the latent variable can be assessed by the observed variable's $R^{2}$ value. The $R^{2}$ value identifies how much of the indicator variable's variance explains the factor. An $R^{2}$ value $\leq .20$ suggests that the observed variable does not adequately describe the factor and should be considered for removal from the model [38].

The following observed variables had $R^{2}$ values $\leq .20$ : HR3, HR4, HR6, and HR7. The $R^{2}$ values, along with the error variances for each observed variable are presented in Table 10.
Table-10: Estimated Error Variances and $\mathbf{R}^{2}$ Values for Each Indicator Variable - Latent Variable Relationship in the CFA model

\begin{tabular}{|l|l|l|}
\hline Endogenous Variable & Standard Error & $R^{2}$ \\
\hline HR1 & 0.06 & 0.95 \\
\hline HR2 & 0.41 & 0.64 \\
\hline HR3 & 0.71 & 0.00 \\
\hline HR4 & 0.51 & 0.01 \\
\hline HR5 & 0.29 & 0.47 \\
\hline HR6 & 0.93 & 0.02 \\
\hline HR7 & 0.39 & 0.03 \\
\hline HR8 & 0.12 & 0.92 \\
\hline
\end{tabular}

Note. -- indicates the statistic could not be calculated

\section{Discriminant validity}

A Pearson correlation analysis was conducted between Self-realization and Health responsibility. Cohen's standard was used to evaluate the strength of the relationship, where coefficients between .10 and .29 represent a small effect size, coefficients between .30 and .49 represent a moderate effect size, and coefficients above .50 indicate a large effect size [39]. Assumptions for Pearson's correlation were checked. Linearity. A Pearson correlation requires that the relationship between each pair of variables is linear [39]. This assumption is violated if there is curvature among the points on the scatterplot between any pair of variables. Figure 5 presents the scatterplot of the correlation. A regression line has been added to assist the interpretation.

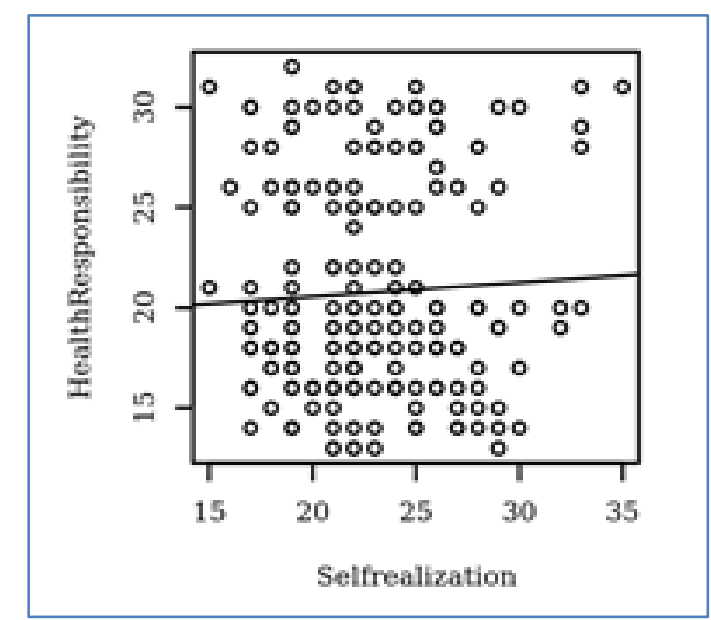

Fig-5: Scatterplots between each variable with the regression line added

The correlations were examined based on an alpha value of 0.05 . There were no significant correlations between any pairs of variables. Table 11 presents the results of the correlation.

Table-11: Pearson Correlation Results between Self-realization and Health Responsibility

\begin{tabular}{|c|c|c|c|c|}
\hline Combination & $r_{\mathrm{p}}$ & Lower & Upper & $p$ \\
\hline Self-realization-Health Responsibility & 0.05 & -0.08 & 0.19 & .447 \\
\hline
\end{tabular}




\section{DISCUSSION}

The aim of this study was to establish psychometric properties of the subscales self-realization and health responsibility of health-promoting lifestyle profile II tool. This validation was done among Kenyan university students. The current study found that the items for Self-realization had a Cronbach's alpha coefficient of 0.72 , indicating acceptable reliability. In addition, the items for health responsibility had a Cronbach's alpha coefficient of 0.80 , indicating good reliability. However, one item was removed because it negatively correlated with the latent variable health responsibility (HR4). Consistent with the current study is a study among undergraduate students in Malaysia which found that the sub-scales of the HPLP showed good psychometric properties and could be used to assess health-promoting behavior among undergraduate students [40]. In their study, all items within the subscales showed a factor loading above 0.40 . The convergent validity was indicated by (Composite Reliability) CR estimates, which ranged from 0.664 to 0.844 . However, the current study used internal consistency (Cronbach alpha) to determine the reliability of the constructs but Bee et al. [40]'s study utilized the Composite Reliability (CR) based on Raykov and Marcoulides [41]. A descriptive crosssectional study with Portuguese adolescents was conducted and found Cronbach coefficients for the subscales of health Responsibility to be 0.825 and Positive Life Perspective to be 0.810 [42]. Consistent with the findings is another study done among Malaysian undergraduate that found the constructs health responsibility and spiritual Growth had a Cronbach coefficient of 0.87 and 0.81 respectively [43]. Finally, an Iranian study found health responsibility had a Cronbach alpha of 0.84 and spiritual growth had a Cronbach of 0.83 [44].

This study applied CFA, which is a type of structural equation modeling that deals specifically with measurement models. CFA examines the strength of the relationship between an observed measure and latent variables or factors, based on factor loading. CFA requires a strong conceptual foundation to guide the specification and evaluation of the factor model. It can be utilized in psychometric evaluation, detection of method effects, construct validation and also for the evaluation of measurement in variance. Since the factors and items of HPLP-II have been predetermined in previous studies, we conducted only a confirmatory study. In the current study the CFS's for the subscales self-realization and health responsibility were analyzed separately. The self-realization model did not fit the data adequately as noted by the chi-square goodness of fit test were significant, $\chi^{2}(27)=251.61, p<.001$ and fit indices. The model for health responsibility also did not adequately fit the data as noted by the Chi-square goodness of fit test were significant, $\chi^{2}(20)=272.58, p$ $<.001$ and fit indices. This is inconsistent with previous studies done $[25,43,44]$. In the current study, the two sub-scales had discriminant validity because there were no significant correlations between the pairs of variables, this was consistent with a study among Malaysian university students where the final measurement model demonstrated discriminant validity [40].

This study cannot be complete without stating the limitations which may have brought about the possible inconsistencies with findings from other studies. The first limitation is with regards to a large number of questions in the questionnaire, the possibility of the students being unable to answer all the questions also affected the study. Another limitation is the use of a self-reported questionnaire, which may be subject to response bias. In order to overcome this limitation, we emphasized the importance of honest feedback to the subjects prior to data collection. Moreover, we are unsure about its generalization among undergraduate students in general until further cross-validation studies are conducted among these populations.

\section{CONCLUSION \& RECOMMENDATION}

In conclusion, within the limitations of this study, it was established that the self-realization and health responsibility subscales of the HPLP-II had good internal consistency with Cronbach alphas of over 0.7. However confirmatory factor analysis could not well fit the items to their latent constructs. This study recommended that in future studies, a shortened version of this tool is subject to psychometric investigation. In addition, further research should examine the replicability of the HPLP-II-M in more diverse Kenyan speaking populations.

\section{ABBREVIATIONS}

CFA: Confirmatory factor analysis; CFI: Comparative fit index; CR: Construct reliability; HPLPII: Health-Promoting Lifestyle Profile II; MLR: Robust maximum likelihood estimator; RMSEA: Root mean square error of approximation; SD: Standard deviation; SRMR: Standardised root mean square; TLI: Tuckerlewis index

\section{ACKNOWLEDGMENTS}

We would like to express our gratitude to the respondents. And not to forget the extraordinary efforts of the field staff.

\section{ETHICAL DISCLOSURES \\ Protection of human and animal subjects}

The authors declare that the procedures followed were in accordance with the regulations of the relevant research ethics committee and with those of the Code of Ethics of the Declaration of Helsinki.

\section{Confidentiality of data}

The authors declare that they have followed the protocols of the university on the publication of the data. 


\section{Right to privacy and informed consent}

The authors have obtained the written informed consent of the patients or subjects mentioned in the article. The corresponding author is in possession of this document.

\section{Competing interest}

The authors declare that they have no competing interests.

\section{Authors\& contributions}

Micky Olutende Oloo and Dr. Maximilla Wanzala conceived the paper, designed and performed the study. Prof Edwin Wamukoya conceived the paper and was the paper's peer reviewer. All authors read and approved the final manuscript.

\section{Funding}

No financial support was provided.

\section{Disclaimer}

The findings and conclusions presented in this manuscript are those of the authors and do not necessarily reflect the official position of Masinde Muliro University of Science and Technology

\section{REFERENCES}

1. World Health Organization.(2015). Health promotion. 2015 [cited 2019 Nov 2]. Available from: topics/healthpromotion/en/.

2. Choo, J.,\& Kang, H. (2015). Predictors of initial weight loss among women with abdominal obesity: a path model using self-efficacy and healthpromoting behaviour. $J$ Adv Nurs. 71(5), 1087-97.

3. Turan, T. N., Al Kasab, S., Nizam, A., Lynn, M. J., Harrell, J., Derdeyn, C. P., ... \& Chimowitz, M. I. (2018). Relationship between risk factor control and compliance with a lifestyle modification program in the stenting aggressive medical management for prevention of recurrent stroke in intracranial stenosis trial. Journal of Stroke and Cerebrovascular Diseases, 27(3), 801-805.

4. Baheiraei, A., Mirghafourvand, M., Mohammadi, E., Nedjat, S., Charandabi, S. M. A., Rajabi, F., \& Majdzadeh, R. (2011). Health-promoting behaviors and social support of women of reproductive age, and strategies for advancing their health: Protocol for a mixed methods study. BMC public health, 11(1), 191.

5. Sohng, K. Y., Sohng, S., \& Yeom, H. A. (2002). Health-promoting behaviors of elderly Korean immigrants in the United States. Public Health Nursing, 19(4), 294-300.

6. Alizadeh, M., \& Ghabili, K. (2008). Health related lifestyle among the Iranian medical students. Res Biol Sci, 3(1), 4-9.

7. Lee, R. L., \& Loke, A. J. Y. (2005). Healthpromoting behaviors and psychosocial well-being of university students in Hong Kong. Public health nursing, 22(3), 209-220.
8. World Health Organization. (2017). Preventing Noncommunicable Diseases (NCDs) Reducing Environmental Risk Factors. Retrieved from http://apps.who.int/iris/bitstream/10665/258796/1/ WHO-FWC-EPE-17.01-eng.pdf?ua=1

9. Machio, P. M. (2012). "The Effect of Chronic Illness on Labor Market Outcomes in Kenya." Center for the Study of Africa Economies. Oxford, UK. https://editorialexpress.com/cgibin/conference/download.cgi?db_name=CSAE201 2\&paper_id $=502$

10. Lee, I. M., Shiroma, E. J., Lobelo, F., Puska, P., Blair, S. N., \& Katzmarzyk, P. T. (2012). Effect of physical inactivity on the world's major noncommunicable diseases. The Lancet, 380(9838), 219-229

11. Chuang, S.P., Wu, J.Y.W., Wang, C.S., \& Pan, L.H. (2017). Health-promoting lifestyles and psychological distress associated with well-being in community adults. Am J Health Behav, 41(4), 44653.

12. Lolokote, S., Hidru, T. H., \& Li, X. (2017). Do socio-cultural factors influence college students' self-rated health status and health-promoting lifestyles? A cross-sectional multicenter study in Dalian, China. BMC public health, 17(1), 478.

13. Walker, S. N., Sechrist, K. R., \& Pender, N. J. (1987). The health-promoting lifestyle profile: development and psychometric characteristics. Nursing research.

14. Hulme, P. A., Walker, S. N., Effle, K. J., Jorgensen, L., McGowan, M. G., Nelson, J. D., \& Pratt, E. N. (2003). Health-promoting lifestyle behaviors of Spanish-speaking Hispanic adults. Journal of Transcultural Nursing, 14(3), 244-254.

15. Wang, Y. J., Wu, L. J., Xia, W., Sun, C., Wei, C., \& Shang, T. (2007). Reliability and validity of Chinese version of the health-promoting lifestyle profile. Chin J Sch Health, 28(10), 889-91.

16. Wei, C. N., Yonemitsu, H., Harada, K., Miyakita, T., Omori, S., Miyabayashi, T., \& UEDA, A. (2000). A Japanese language version of the healthpromoting lifestyle profile. Nippon Eiseigaku Zasshi (Japanese Journal of Hygiene), 54(4), 597606.

17. Meihan, L., \& Chung-Ngok, W. (2011). Validation of the psychometric properties of the healthpromoting lifestyle profile in a sample of Taiwanese women. Quality of Life Research, 20(4), 523-528.

18. Callaghan, D. M. (2003). Health-promoting selfcare behaviors, self-care self-efficacy, and self-care agency. Nursing Science Quarterly, 16(3), 247254.

19. Hambleton, R. K., Merenda, P. F., \& Spielberger, C. D. (2004). Issues, designs, and technical guidelines for adapting tests into multiple languages and cultures. In Adapting educational 
and psychological tests for cross-cultural assessment (pp. 15-50). Psychology Press.

20. Ferguson, E., \& Cox, T. (1993). Exploratory factor analysis: A users' guide. International journal of selection and assessment, 1(2), 84-94.

21. Shah, R., \& Goldstein, S. M. (2006). Use of structural equation modeling in operations management research: Looking back and forward. Journal of Operations management, 24(2), 148-169.

22. Bryman, A., \& Cramer, D. (1997). Quantitative data analysis with SPSS for Windows: A guide for social scientists. Routledge.

23. Walker, S.N., Sechrist, K., \& Pender, N.J. (2007). The Health-promoting Lifestyle Profile II. (Updated 2007 April 25; cited 2007 May 20). Available from URL: http://app1.unmc.edu/nursing/conweb/HPLPII_Abs tract_Dimensions.pdf

24. Walker, S.N., Sechrist, K.R.,\& Pender, N.J. (1995). Health promotion model-instruments to measure health promoting lifestyle: health-promoting lifestyle profile [HPLP II] (adult version). 1995. https://deepblue.lib.umich.edu/bitstream/handle/20 27.42/85349/HPLP_II-

background_and_permission.pdf?sequence $=1 \&$ isall owed $=\mathrm{y}$.

25. Sousa, P., Gaspar, P., Fonseca, H., Hendricks, C., \& Murdaugh, C. (2015). Health promoting behaviours in adolescence: validation of the Portuguese version of the Adolescent Lifestyle Profile. J Pediatr (Rio $J$ ). http://dx.doi.org/10.1016/j.jped.2014.09.005

26. Mohamadian, H., Ghannaee, M., Kortdzanganeh, J.\& Meihan, L. (2013). Reliability and construct validity of the Iranian version of health-promoting lifestyle profile in a female adolescent population. Int J Prev Med, 4(1), 42.

27. Bahar, Z., Beser, A., Gordes, N., Ersin, F., \& Kissal, A. (2008). Healthy Life Style Behavior Scale II: A Reliability and Validity Study. Journal of Cumhuriyet University School of Nursing, 12, 1.

28. DeVon, H. A., Block, M. E., Moyle-Wright, P., Ernst, D. M., Hayden, S. J., Lazzara, D. J., ... \& Kostas-Polston, E. (2007). A psychometric toolbox for testing validity and reliability. Journal of Nursing scholarship, 39(2), 155-164.

29. Munder, T., Wilmers, F., Leonhart, R., Linster, H. W., \& Barth, J. (2010). Working Alliance Inventory-Short Revised (WAI-SR): psychometric properties in outpatients and inpatients. Clinical psychology \& psychotherapy, 17(3), 231-239.

30. de Melo Ghisi, G. L., Grace, S. L., Thomas, S., Evans, M. F., \& Oh, P. (2013). Development and psychometric validation of a scale to assess information needs in cardiac rehabilitation: The
INCR Tool. Patient education and counseling, 91(3), 337-343.

31. Ravens-Sieberer, U., Erhart, M., Rajmil, L., Herdman, M., Auquier, P., Bruil, J., ... \& Mazur, J. (2010). Reliability, construct and criterion validity of the KIDSCREEN-10 score: a short measure for children and adolescents' well-being and healthrelated quality of life. Quality of Life Research, 19(10), 1487-1500.

32. Westfall, P. H., \& Henning, K. S. S. (2013). Texts in statistical science: Understanding advanced statistical methods. Boca Raton, FL: Taylor \& Francis.

33. George, D., \& Mallery, P. (2016). SPSS for Windows step by step: A simple guide and reference, 11.0 update (14 ${ }^{\text {th }}$ ed.). Boston, MA: Allyn and Bacon.

34. DeCarlo, L. T. (1997). On the meaning and use of kurtosis. Psychological Methods, 2(3), 292-307

35. Newton, R. R., \& Rudestam, K. E. (2012). Your statistical consultant. Thousand Oaks, CA: Sage Publications.

36. Kline, R. B. (2015). Principles and practice of structural equation modeling. New York, NY: Guilford Publications.

37. Field, A. (2013). Discovering statistics using SPSS (4th ed.). Thousand Oaks, CA: Sage.

38. Hooper, D., Coughlan, J., \& Mullen, M. (2008). Structural equation modelling: Guidelines for determining model fit. Electronic Journal of Business Research Methods, 6(1), 53-60.

39. Cohen, M. A. (1988). Some new evidence on the seriousness of crime. Criminology, 26(2), 343-353.

40. Lim, B. C., Kueh, Y. C., Arifin, W. N., \& Ng, K. H. (2016). Validation of Health Promoting Lifestyle Profile-II: A Confirmatory Study with a Malaysian Undergraduate Students Sample. Education in Medicine Journal, 8(2).

41. Raykov, T., \& Marcoulides, G. A. (2016). Scale reliability evaluation under multiple assumption violations. Structural Equation Modeling: A Multidisciplinary Journal, 23(2), 302-313.

42. Sousa, P., Gaspar, P., Vaz, D.C., Gonzaga, S., \& Dixe, M.A. (2015). Measuring health promoting behaviours: cross-cultural validation of the healthpromoting lifestyle profile-II. In J Nurs Knowl, 26(2), 54-61.

43. Kuan, G., Kueh, Y. C., Abdullah, N., \& Tai, E. L. M. (2019). Psychometric properties of the healthpromoting lifestyle profile II: cross-cultural validation of the Malay language version. $B M C$ public health, 19(1), 751 .

44. Tanjani, P.T., Azadbakht, M., Garmaroudi, G., Sahaf, R., \& Fekrizadeh, Z. (2016). Validity and reliability of health promoting lifestyle profile II in the Iranian elderly. Int J Prev Med, 7, 74. 